\title{
Zinc Serum Level Can Be A Risk Factor In Babol Stroke Patients?
}

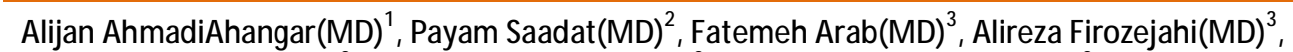

M ohamad Ali Biani(MD) ${ }^{3}$, Reza Sohrabnezhad(MD) ${ }^{3}$, Hamed Hosseinzadeh(M Sc $)^{3}$, Roughaie M ortazavinezhad(BSc) ${ }^{3}$, Sekine Faraji(BSc) $)^{3}$, Fatemeh Farajzadeh(BSC) $)^{3}$, Shayan Alijanpour $(B S C)^{4 *}$

${ }^{1}$ Associated professor of Neurology, M obility Impairment Research Center, Babol University of M edical Sciences, Babol, Iran

${ }^{2}$ Assistant professor of Neurology, Rouhani Hospital, Babol University of Medical Sciences, Babol, Iran

${ }^{3}$ Babol university of medical science, Babol, Iran

${ }^{4}$ Emergency M edical Service Center, Babol university of medical science, Babol, Iran

*Corresponding Author: Email: Alijanpour.sh@live.com

Background and Purpose: Stroke is the second leading cause of death worldwide. The role of zinc as a contributing factor in the pathogenesis of stroke was considered.

Results: This cross-sectional study on 100 stroke patients in Ayatollah Rouhani Hospital and 100 control group from cohort master plan "Ageing and health projects Amirkola was conducted. Zinc levels Serum simultaneously with other blood tests in the early hours of hospitalization. Zinc serum level was defined 70 to 120 micrograms per deciliter.

Findings: The difference in mean of zinc level in patients and control group was not significant (102.6 \pm 47.7 in control group vs $100.9 \pm 35.8$ in patient, $p=0.7)$. Difference in zinc Serum level had statically significant with IHD (under70 0 cases (0), 70 tol20 8 cases (24), 120 and upper24 cases (75), $p=0.003$ ) and with type of stroke (under70 (3(3.3) hemorrhagic vs $0(0)$ ischemic), 70 to $120(19(21)$ vs6 (60)), 120 and upper68 (75.6) vs4 (40), $p=0.025)$ and also with patient and control group (under70 (3(3) in patient's vs 20(20) control group), 70 to 120 (25(25) vs54 (54)), 120 and upper72 (72) vs26 (26), $p<0001$ ). In patients group 72(73.5) of cases had zinc serum level above 120. HLP difference was significant in patient and control group (50(50) in control group vs 35(35) in patients, $p=0.04$ ). Regression logistic show that IHD ( $p \varangle 0001, \mathrm{OR}=30, \mathrm{Cl}=6-152), \mathrm{HLP}(\mathrm{p} \varangle 0001, \mathrm{OR}=4, \mathrm{Cl}=9.09-1.85)$, zinc serum level $(p \varangle 001, O R=15.5, C l=4-59.8)$ had significant role.

Conclusions: Zinc serum levels, Ischemic Heart Disease, Hyperlipidemia were most risk factor that play role in Babol stroke patients.

Key words: Stroke, Risk factors, Zinc

DOI: $10.7575 /$ aiac.abcmed.ca1.10

Published Date: February 2017

Peer-review is under responsibility of the 9th Iranian Stroke Congress.

Published by Australian International Academic Centre, Australia

This published work is open access under the CC BY license.

Available online at www.abcmed.aiac.org.au 